\title{
Mechanical Properties of Highly Porous Super Liquid-repellent Surfaces
}

Maxime Paven, Regina Fuchs, Taro Yakabe, Doris Vollmer, Michael Kappl, Akiko N. Itakura, and Hans-Jürgen Butt*

M. Paven, Dr. R. Fuchs, Prof. D. Vollmer, Dr. M. Kappl, Prof. H.-J. Butt Ackermannweg Max Planck Institute for Polymer Research, Ackermannweg 10, D-55128 Mainz, Germany

E-mail: butt@mpip-mainz.mpg.de

T. Yakabe, Prof. A. Itakura

National Institute for Materials Science, 1-2-1 Sengen, Tsukuba, Ibaraki, 305-0047, Japan

The poor mechanical properties of highly porous materials restrict their utilization for applications such as super liquid-repellent coatings. The design principles of super liquidrepellent surfaces aim at maximizing roughness at the nano or micrometer scale, making them inherently mechanically weak. To find a balance between liquid repellency and mechanical stability investigation of the surfaces's mechanical properties is essential. Here, we applied atomic and colloidal probe force measurements, nanoindentation, pencil and finger scratching to investigate the mechanical properties of super liquid-repellent surfaces prepared by soot templating. In particular the colloidal probe technique is suitable to characterise the mechanical strength of super liquid-repellent surfaces because it covers the right force and length scale. We propose four parameters to describe the mechanical response: The effective elastic modulus $E_{\text {eff, }}$ the maximum indentantion force $F_{\max }$, the plastic work of indentation $W_{\text {plastic }}$ and the effective adhesive work $W_{\text {adhesive. }}$ We varied the reaction paramteres, i.e. the thickness of the template-stabilizing silica shell and the sintering temperature to investigate their influence on the wetting and mechanical properties. Sintering at $1000{ }^{\circ} \mathrm{C}$ increased the effective elastic modulus of the surface by more than an order of magnitude. Sintering at $1150{ }^{\circ} \mathrm{C}$ led to a smoothening of the porous silica network and the effective elastic modulus increased by up to five orders of magnitude. At the same time, however, for droplets of $n$-hexadecane the roll-off angle increased and the receding contact angle decreased.

\section{Introduction:}

Super liquid-repellent surfaces, or so-called superhydrophobic or superamphiphobic surfaces gained much attention [1] [2] [3] [4] [5] due their potential applications e.g. as self-cleaing coatings ${ }^{[6]}$, as membrane coatings for gas exchange ${ }^{[7][8]}$ or to supress the formation of biofilms. ${ }^{[9]}$ Liquid drops resting on these surfaces exhibit receding contact angles of more than $\approx 140^{\circ}$ and easily roll-off at tilting angles lower than $10^{\circ}$. The excellent liquid repellency results from a low contact area of the drop, with a substrate. Hereby, the drop rests on the top faces of the protrusions or asperities, separated from the substrate by air cushions. ${ }^{[10]}$ [11] The receding contact angle of the surface increases with the average distance of the 
protrusions and decreasing width. ${ }^{[12]}$ To achieve super liquid-repellency surface protrusions on the $\mu \mathrm{m}$ or $\mathrm{nm}$ scale are mandatory. ${ }^{[13]}[14,15]$

From these prerequisites, it follows that super liquid-repellent surfaces are prone to mechanical stress because the external force is distributed upon the surface protrusions and not the entire projected area. Once a critical pressure or shear is exceeded, the surface protrusions break. ${ }^{[16]}$ As a result, the surface loses its liquid repellency. ${ }^{[17]}[18,19]$ Unfortunately, gaining good liquid repellency demands a different design for the surface morphology than optimizing for high mechanical strength. For example, with respect to arrays of micropillars the receding contact angle is high when choosing thin micropillars and a larger spacing between the pillars. ${ }^{[15]}$ In contrast, for a good mechanical shear strength the micropillars should be thick and narrowly spaced. Thus, for a given application the design needs to be carefully optimized. Accessing the mechanical properties is an essential part of surface improvement.

In this work we focus on the mechanical properties of super liquid-repellent surfaces formed by a porous network of connected particles. Such surfaces can readily be prepared by the bottom up technique, i.e. gradually building up the surface starting from the substrate. Surfaces can e.g. be formed by wet chemistry or thermal processes. Precursor solutions can contain various combinations of monomers, particles and hydrophobization agents and can be drop, spin, dip or (electro)spray coated on various substrates. ${ }^{[20]}[21]$ [22] [23] [19] [24] [4] Thermally induced surface roughness can be achievede.g. by flame coating of sol-gels or combustion of organic compounds. ${ }^{[25]}{ }^{[26]}$. Both techniques are appealing due to their simplicity and adaptability to coat large areas and various substrates. Unfortunately, the obtained surfaces often suffer from low mechanical stability.

The quantification and comparison of mechanical properties remains unsatisfactory. One of the reason is that the mechanical properties of super liquid-repellent surfaces can span a wide range. Qualitative tests e.g. the pencil hardness (ISO 15184 and ASTM D3363), (nano)wear abrasion ${ }^{[27] ~[28] ~[29], ~ s a n d ~(A S T M ~ D 968) ~ o r ~ l i q u i d ~ j e t ~ i m p a c t ~}{ }^{[30]}$ are fast and convenient. However, they generally only allow for a rough comparison and not for detailed insights into the surface mechanical properties. Ideally, mechanical stability of samples is compared using quantitative properties, like the effective elastic modulus. Quantitative properties can be obtained by force sensitive measurements.

Here, we used complementary methods to characterize the mechanical properties of super liquid-repellent surfaces, more specifically to get a comprehensive view of candle-soot templated surfaces. To cover different force ranges we used atomic force microscopy $(\mathrm{AFM})^{[31][32]}$ and nanoindentation ${ }^{[33]}$. We explicitely demonstrate that force measurments with microsphere ("colloidal probe") ${ }^{[34][35][36][37]}$ instead of sharp AFM tips allow to asses the mechanical properties of soot-templated surfaces. The colloidal probe technique closes a gap of sensitivity vs. probing area and allows to characterize the mechanical properties of fragile surfaces. The analysis of the mechanical stability is crucial to understand and improve the preparation process of super liquid-repellent surfaces. 


\section{Results and Discussion:}

Soot-templated surfaces as introduced by Deng et al. ${ }^{[26]}$ served as model system for fractal like, highly porous super liquid-repellent surfaces (Figure 1a). Soot consists of a highly porous network of carbon nanoparticles. The nanoparticles have a diameter of about $40 \mathrm{~nm}$ and are loosely connected by van der Waals forces. The fragile carbon network was stabilized by deposition of a silica shell by chemical vapor deposition (CVD) of tetraethyl orthosilicate (TEOS) for 24, 48 and $72 \mathrm{~h}$, which we refer to as coated soot. The thickness of the deposited silica layer increased with CVD time and ranged from 20-35 nm, 35-71 nm and 60-100 nm for $24 \mathrm{~h}, 48 \mathrm{~h}$ and $72 \mathrm{~h}$, respectively. The coated soot was sintered at $600{ }^{\circ} \mathrm{C}, 800$ ${ }^{\circ} \mathrm{C}, 1000{ }^{\circ} \mathrm{C}$ or $1150{ }^{\circ} \mathrm{C}$ for $3 \mathrm{~h}$. The sintered samples are refered to as soot-templated silica. Hydrophobization of coated soot and soot-templated silica with a fluorosilane led to superamphiphobic surfaces, that is water and oil repellent surfaces. In the following, we investigated the influence of the sintering temperature and the time of CVD on the wetting and mechanical properties of the surfaces.

(a)

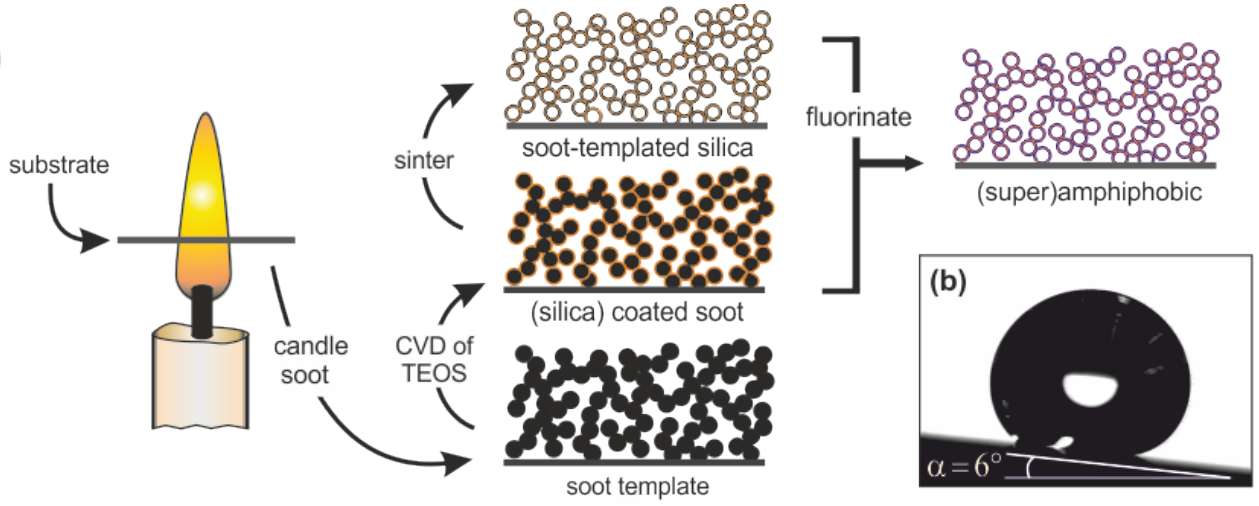

(c)

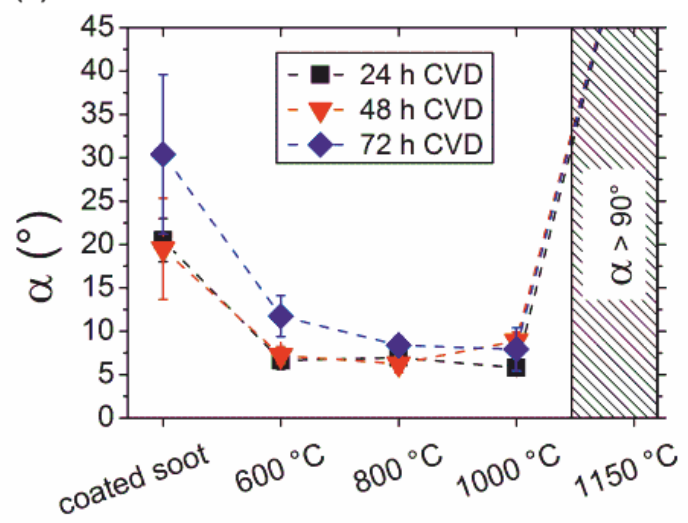

(d)

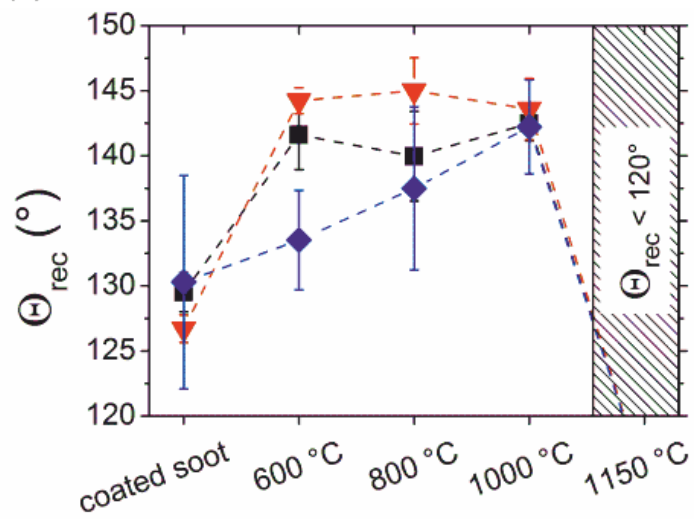

Figure 1: (a) Scheme of sample preparation: Collection of candle soot on the substrate. Silica is deposited by chemical vapor deposition CVD, of TEOS. Afterwards, the coated soot was sintered at various temperatures. Finally, a fluorosilane was deposited to lower the surface energy and make the surfaces liquid-repellent. (b) Image of a hexadecane drop $(\gamma=27.5 \mathrm{~N} / \mathrm{m}$, $6 \mathrm{\mu l}$ ) rolling off at $6^{\circ}$ from a sample exposed to $24 \mathrm{~h} \mathrm{CVD} \mathrm{sintered} \mathrm{at} 600^{\circ} \mathrm{C}$. (c) Roll-off angles $\alpha$ and (d) receding contact angles $\theta_{\text {rec }}$ of hexadecane on candle-soot based superamphiphobic surfaces as function of CVD time and sintering temperature. 


\section{Wetting properties}

Fluorinated coated soot and soot-templated silica surfaces $\left(600-1000{ }^{\circ} \mathrm{C}\right)$ were superhydrophobic. Water drops (6 $\mu \mathrm{l}$ ) rolled off at inclination angles $\alpha$ of $1 \pm 1^{\circ}$, the receding contact angles were $>140^{\circ}$. On samples sintered at $1150{ }^{\circ} \mathrm{C}$ the receding contact angles of water were also above $140^{\circ}$ and water drops rolled off at $10 \pm 3^{\circ}, 5 \pm 2^{\circ}$ and $8 \pm 2^{\circ}$ for CVD periods of $24 \mathrm{~h}, 48 \mathrm{~h}$ and $72 \mathrm{~h}$, respectively.

Furthermore, wetting properties were tested with hexadecane (Figure 1b, Figure S1). Samples sintered at $600-1000{ }^{\circ} \mathrm{C}$ showed the best repellency and were superamphiphobic. Drops of hexadecane rolled off at low angles of less than $10^{\circ}$ and showed high receding contact angles. Samples sintered at $1150{ }^{\circ} \mathrm{C}$ were superhydrophobic but lost superamphiphobicity, i.e. roll of angles of hexadecane were $>90^{\circ}$. Also, coated soot showed higher roll-off and lower receding contact angles. This is attributed to van der Waals interaction between hexadecane and the soot template because the silica shell is porous before sintering ${ }^{[38]}$. With respect to CVD time samples exposed longer to CVD (72 h), thus having a thicker silica shell, showed slightly higher roll-off angles and lower receding contact angles. TEM images of samples exposed to $72 \mathrm{~h}$ CVD revealed that the protrusions, responsible for oil repellency, were smoothened by the deposited silica (Figure S2).

\section{Finger and pencil scratching}

Superhydrophobic soot-templated silica sintered at $1150{ }^{\circ} \mathrm{C}$ showed a strongly increased stability against finger scratching. Such surfaces withstood several finger scratches in contrast to superamphiphobic samples sintered below $1150{ }^{\circ} \mathrm{C}$ (Movie S1). To check the mechanical stability more quantitatively, the surfaces were scratched with a soft $6 \mathrm{~B}$ pencil at an angle of $45^{\circ}$ and low loads of about $10 \mathrm{~g}$. The scratches were investigated by SEM (Figure 2) and optical microscopy (Figure S3). Soot-templated silica sintered below $1150{ }^{\circ} \mathrm{C}$ was removed by scratching (Figure $2 \mathrm{a}$ and $\mathrm{b}$, Figure S3a-e). In contrast, the soot-templated silica sintered at $1150{ }^{\circ} \mathrm{C}$ was only partially removed (Figure $2 \mathrm{e}$ and $\mathrm{f}$, Figure S3f). Besides, we observed chipping of the rims with increasing period of CVD (Figure S3c compared to a). This indicates a strengthening of the cohesive forces of the silica network with increasing CVD duration. Though the pencil scratch test is only recommended for smooth surfaces (ISO 15184) we found it useful for surfaces with a significant difference in mechanical stability as presented in our case to distinguish between samples sintered at and below $1150{ }^{\circ} \mathrm{C}$. 

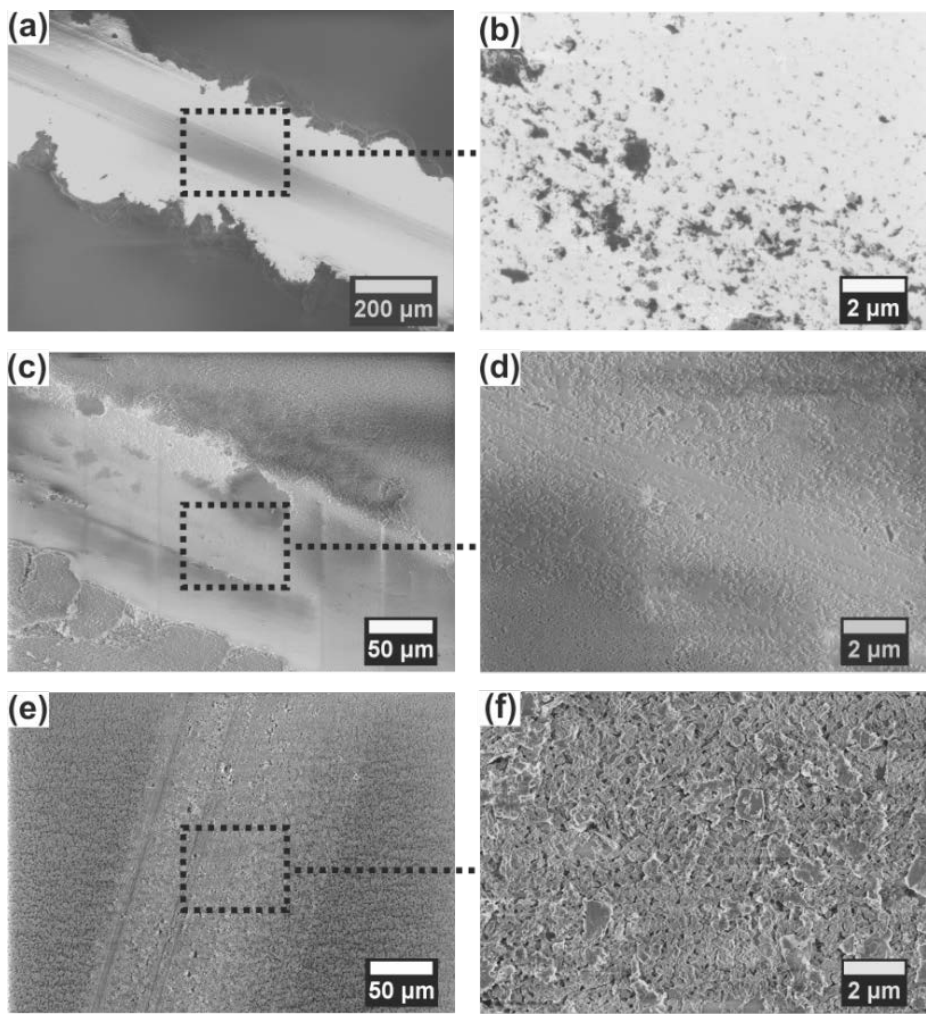

Figure 2: SEM images of soot-templated silica surfaces after scratching with a 6 B pencil. Surfaces were exposed to $24 \mathrm{~h}$ of CVD and sintered at $600{ }^{\circ} \mathrm{C}(\mathrm{a}, \mathrm{b}), 100{ }^{\circ} \mathrm{C}(\mathrm{c}, \mathrm{d})$, and $1150^{\circ} \mathrm{C}$ $(e, f)$. Right images: magnification of scratched areas (dotted rectangles in $a, c$ and $e$ ).

\section{Morphology}

The mechanical response of a surface depends on its morphology. In top view, coated soot and soot-templated silica sintered up to $1000{ }^{\circ} \mathrm{C}$ had a similar surface morphology. The networks showed well pronounced protrusions (Figure 3a-e and Figure S4, a). The characteristic mesh sizes of the networks estimated from the average distance of protrusions at the top of the surfaces were of the order of $1 \mu \mathrm{m}$. In contrast, samples sintered at $1150{ }^{\circ} \mathrm{C}$ showed a web-like morphology made of connected strings (Figure $\mathbf{3 f}$, Figure $\mathrm{S} 4 \mathrm{~b}$ and $\mathrm{c}$ ). 


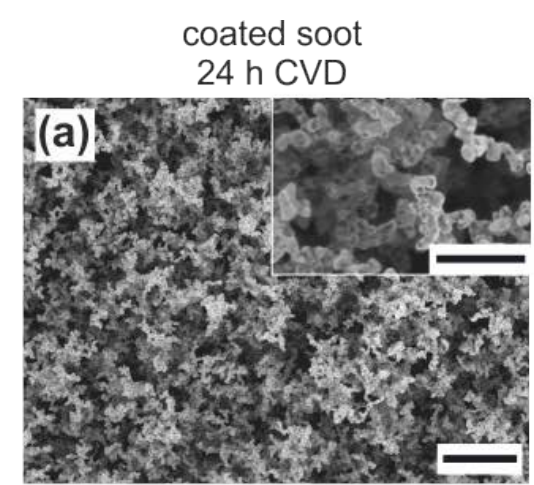

$1000^{\circ} \mathrm{C}$

24 h CVD

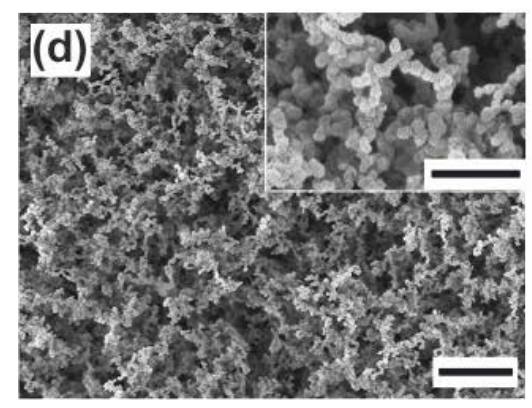

$600{ }^{\circ} \mathrm{C}$

$24 \mathrm{~h}$ CVD

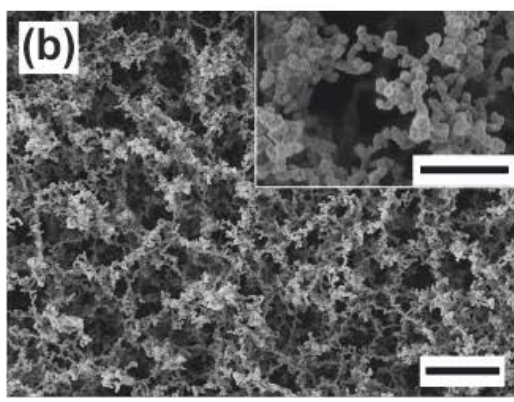

$1000^{\circ} \mathrm{C}$

72 h CVD

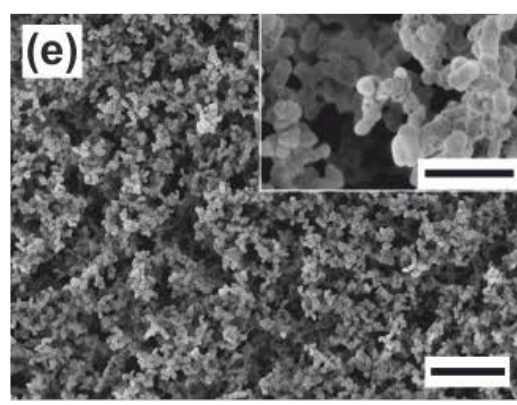

$600{ }^{\circ} \mathrm{C}$

72 h CVD

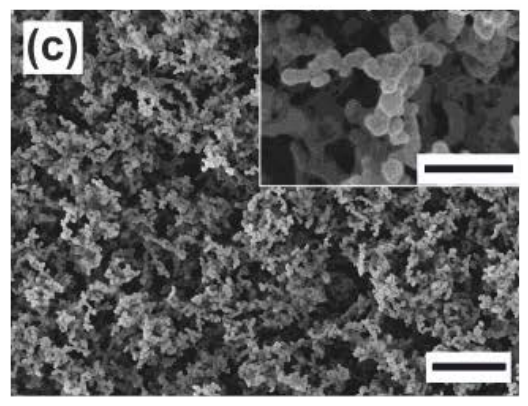

$1150^{\circ} \mathrm{C}$

24 h CVD

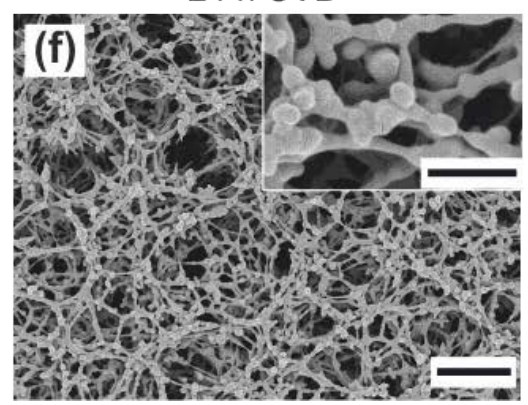

Figure 3: SEM images of soot templated surfaces exposed to different periods of CDV and sintering temperatures. (a) shows coated soot exposed to $24 \mathrm{~h} \mathrm{CVD}$. (b-f) show soottemplated silica sintered at $600{ }^{\circ} \mathrm{C}(\mathrm{b}$ and $\mathrm{c}), 1000^{\circ} \mathrm{C}\left(\mathrm{d}\right.$ and e) and $1150{ }^{\circ} \mathrm{C}(\mathrm{f})$, respectively. (b, $d$ and f) were exposed to $24 \mathrm{~h} \mathrm{CVD,} \mathrm{(c)} \mathrm{and} \mathrm{(e)} \mathrm{were} \mathrm{exposed} \mathrm{to} 72 \mathrm{~h}$ CVD. The scale bar of the SEM images is $2 \mu \mathrm{m}$. The scale bar of the inset is $500 \mathrm{~nm}$.

Though $1150{ }^{\circ} \mathrm{C}$ is well below the melting point of amorphous bulk $\mathrm{SiO}_{2}\left(1713^{\circ} \mathrm{C}\right)$, the strong temperature dependency of the viscosity of silica leads to significant viscous sintering at such temperatures. ${ }^{[39]}{ }^{[40]}$ The viscous flow is driven by the surface tension, leading to a growth of the sinter necks by filling the menisci. ${ }^{[41]}$ Therefore, sintering leads to a reduction of overhanging topography which is essential for superoleophobicity. Furthermore, crosssections of samples with identical initial surface layer thickness showed that sintering at $1150{ }^{\circ} \mathrm{C}$ resulted in a pronounced compaction of surfaces layers. Surfaces treated at $600{ }^{\circ} \mathrm{C}$, $24 \mathrm{~h}$ CVD, had a thickness of $62 \pm 5 \mu \mathrm{m}$ whereas samples treated at $1150^{\circ} \mathrm{C}$ had a thickness of $4 \pm 1 \mu \mathrm{m}(24 \mathrm{~h} \mathrm{CVD})$ and $9 \pm 1 \mu \mathrm{m}$ (72 h CVD), respectively (Figure S3). The strong shrinkage reduced the network's porosity and led to increased stability.

\section{Nanoscale mechanical test with the atomic force microscope}

To test mechanical properties at the nanoscale we performed force measurements using an AFM. The nominal tip radius was 5-10 $\mathrm{nm}$. Thus, it was much smaller than the characteristic size of the silica protrusions ( $>80 \mathrm{~nm}$ ) and the average distance between silica protrusions (about $1 \mu \mathrm{m}$ ). As one example Figure 4a shows a typical force curve measured on a superamphiphobic layer after $24 \mathrm{~h} \mathrm{CVD}$ and sintered at $600{ }^{\circ} \mathrm{C}$. Force jumps of up to $10 \mathrm{nN}$ were observed in the approach and about 2-5 $\mathrm{nN}$ in the retract curves. The force jumps in the approach part are attributed to a local breaking and compression of single sintering 
necks. The broken and dislocated pieces stay either in contact with the protrusion or the tip, attracted by surfaces forces. ${ }^{[42]}{ }^{[43]}$ These surface forces are in particular van der Waals forces. In addition, capillary forces can arise because the fractured areas are hydrophilic, water can condense into the gap between two pieces, form a meniscus and cause strong attraction. Furthermore, during the breaking, electric charges may be creating leading to electrostatic forces. On the $100 \mathrm{~nm}$ scale these surface forces completely dominate over gravitational forces.

These surface forces also cause the strong adhesion observed when retracting the tip. We attribute the jumps in the retract part to rearrangements of the agglomerates of broken pieces. The agglomerates are formed during the approach by breaking individual protrusions. They act like a glue, connecting the tip with the still intact parts of the superamphiphobic layer ${ }^{[44]}{ }^{[45]}$. The final jump is the detachment of the tip from the last protrusion. We estimate the van der Waals force of the final jump by $F=A R / 6 D^{2}$. Here, $\mathrm{A}$ is the Hamaker constant $\left(\approx 6 \times 10^{-20} \mathrm{~J}\right), \mathrm{R}$ is the radius of curvature of the tip and $D$ is the distance at contact $(\approx 0.16 \mathrm{~nm})$. With $\mathrm{R}=10 \mathrm{~nm}$ we estimate a van der Waals adhesion of 4 $\mathrm{nN}$. This agrees with the force measured. The height of the jumps in the approach and retract part of the force-displacement curves differed from position to position because the force was punctually applied and dissipated into the network as schematically shown in Figure 4b. As a conclusion, probes much smaller than the characteristic spacing between protrusions provide information on the mechanical strength of individual protrusions, sintering necks and single agglomerates.

(a)

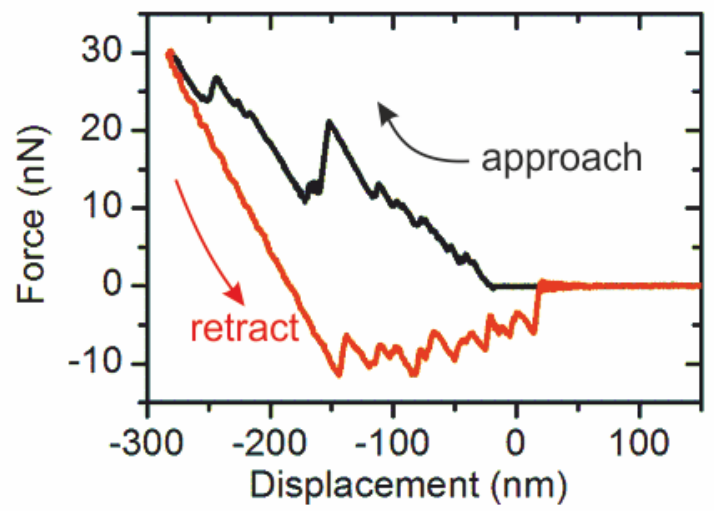

(b)

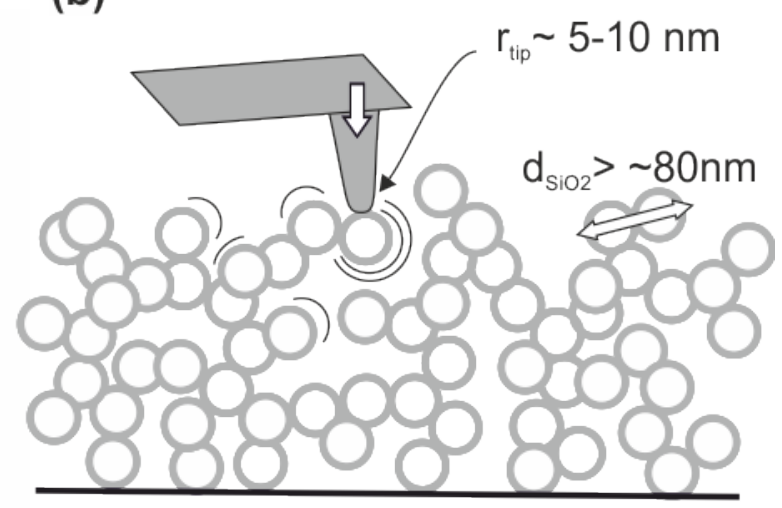

Figure 4: (a) Force-displacement curve of a soot-templated silica surface treated for $24 \mathrm{~h}$ CVD and sintered at $600{ }^{\circ} \mathrm{C}$. (b) Schematic indentation of a candle-soot templated superamphiphobic surface by a sharp AFM tip. The probe radius is about $5 \mathrm{~nm}$ and thus much smaller than the typical size of silica protrusions (>80 nm).

\section{Microscale mechanical tests using Colloidal Probe}

For most industrial or outdoor applications of super liquid-repellent surfaces the collective mechanical properties on a micro or macro scale are more important, e.g. to withstand rain 
droplets or impacting dust particles. Therefore, we increased the indentation area by replacing the sharp AFM tip with a microsphere ("colloidal probe") with a radius of $24 \mu \mathrm{m}$. The colloidal probe was approached onto the surface until a load of $300 \mathrm{nN}$ was reached, followed by a further constant approach of $200 \mathrm{~nm}$. Then it was retracted again. Since the thickness of soot-templated surfaces was chosen to be larger than $20 \mu \mathrm{m}$, the indentation depth was always kept below $10 \%$ of the total layer thickness in order to avoid substrate effects. At an indent of $2 \mu \mathrm{m}$ and a probe radius of $24 \mu \mathrm{m}$ the contact area can be estimated to be of the order of $(17 \mu \mathrm{m})^{2}$. As a result, force curves recorded with the colloidal probe looked smoother (Figure $\mathbf{5}$ and $\mathbf{6}$ ) because the force is an average over many protrusions.

(a)

(b)

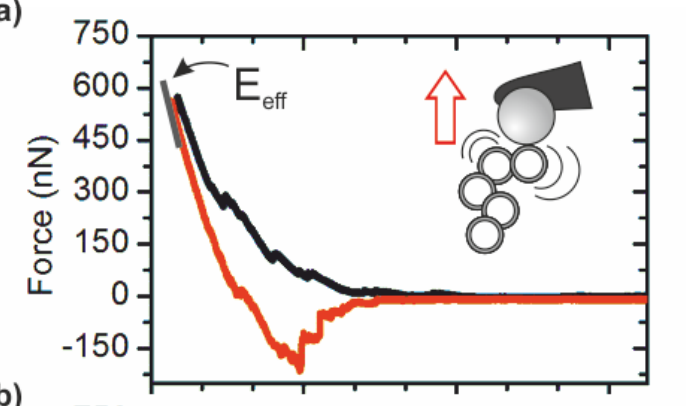

(c)
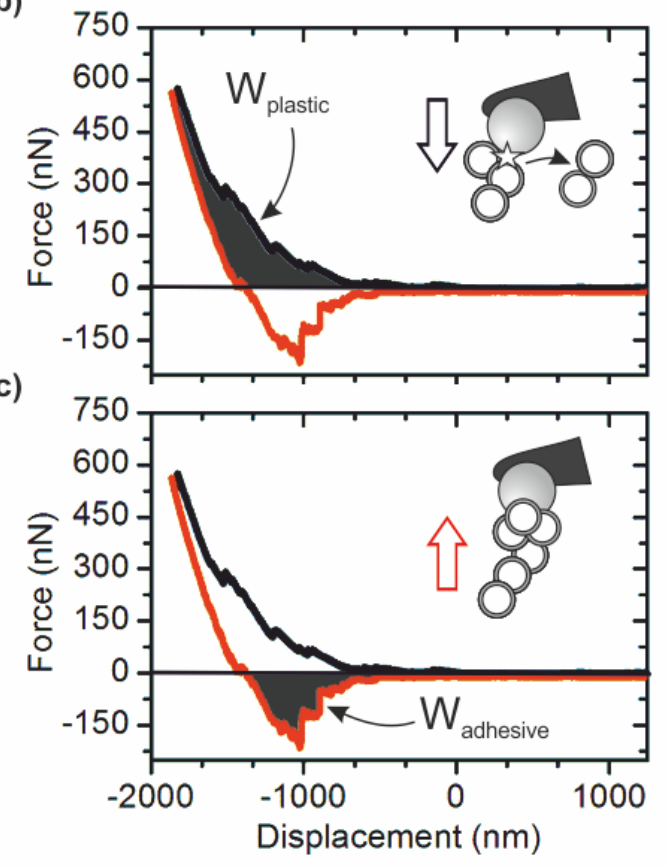

Figure 5: Mechanical properties extracted from typical force-displacement curves: (a) effective elastic modulus $E_{\text {eff, }}$ (b) work of plastic deformation $W_{\text {plastic }}$ and (c) effective work of adhesion, $W_{\text {adhesion. }}$.

For a quantitative characterization of the mechanical properties of superamphiphobic surfaces we defined and analyzed four parameters (Figure 5 and Figure 6a). (1) The effective elastic modulus $E_{\text {eff }}$ is obtained from the elastic recovery upon unloading, i.e. from the slope of the onset of the retract curve. It is characteristic for the ability of the surface layer to store elastic energy upon compression. (2) The maximum indentation force $F_{\max }$, that had to be applied to reach a fixed indentation depth, is related to the material hardness, i.e. its ability to withstand plastic deformation. (3) The plastic work $W_{\text {plastic }}$ and the effective adhesive work $W_{\text {adhesive }}$ are given by the integrals of the force with the $x$-axis on approach and retract, respectively (highlighted area in Figure $5 b$ and $c$ ). They reflect the amount of 
energy consumed in plastically deforming the sample upon approach ( $W_{\text {plastic }}$ ) e.g. due to breakage of contacts within the silica agglomerates, and the energy needed to break the contact upon retract ( $\left.W_{\text {adhesive }}\right)$, due to van der Waals interactions between tip and the silica agglomerates that undergo rearrangement and detachment. As an example, indents obtained from three different samples are compared in Figure 6. The weakest sample (Figure $6 \mathrm{a}, 24 \mathrm{~h} \mathrm{CVD}, 600^{\circ} \mathrm{C}$ ) was indented by almost $2 \mu \mathrm{m}$ even at a relatively low end load of $F_{\max }=350 \mathrm{nN}$ and showed the lowest overall slope in the contact part. The most stable sample (Figure $6 \mathrm{c}, 24 \mathrm{~h} \mathrm{CVD}, 1000^{\circ} \mathrm{C}$ ) was only indented for $900 \mathrm{~nm}$ although the maximum force of $700 \mathrm{nN}$ was much higher. Accordingly, the slope of the force curve was much steeper. The sample prepared by $72 \mathrm{~h} \mathrm{CVD}$ and sintered at $600{ }^{\circ} \mathrm{C}$ showed an intermediate behavior (Figure 6b). The approach curves were smooth for $24 \mathrm{~h} \mathrm{CVD}$ and sintering at $600^{\circ} \mathrm{C}$. They became less smooth exhibiting pronounced force jumps with increasing silica thickness and sintering temperature, indicating an increase in mechanical stability. $F_{\max }$ increased with increasing silica shell thickness and sintering temperature. Force jumps in the retract curves originate from stepwise rearrangement and detachment of loose silica agglomerates while the probe is retracted. Some agglomerates even remained attached to the probe (Figure S5).

(a)

(b)

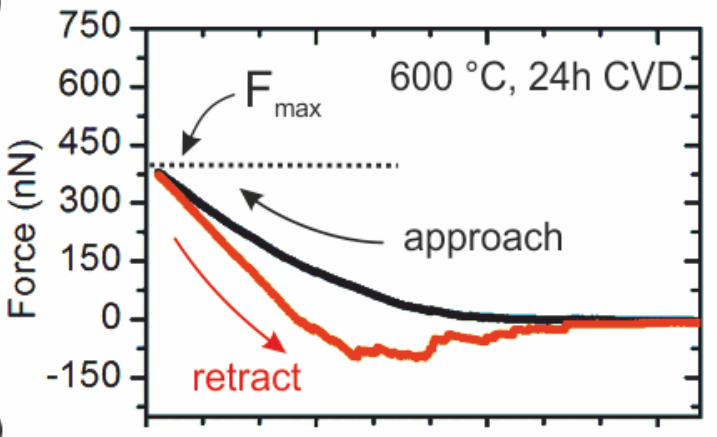

(c)

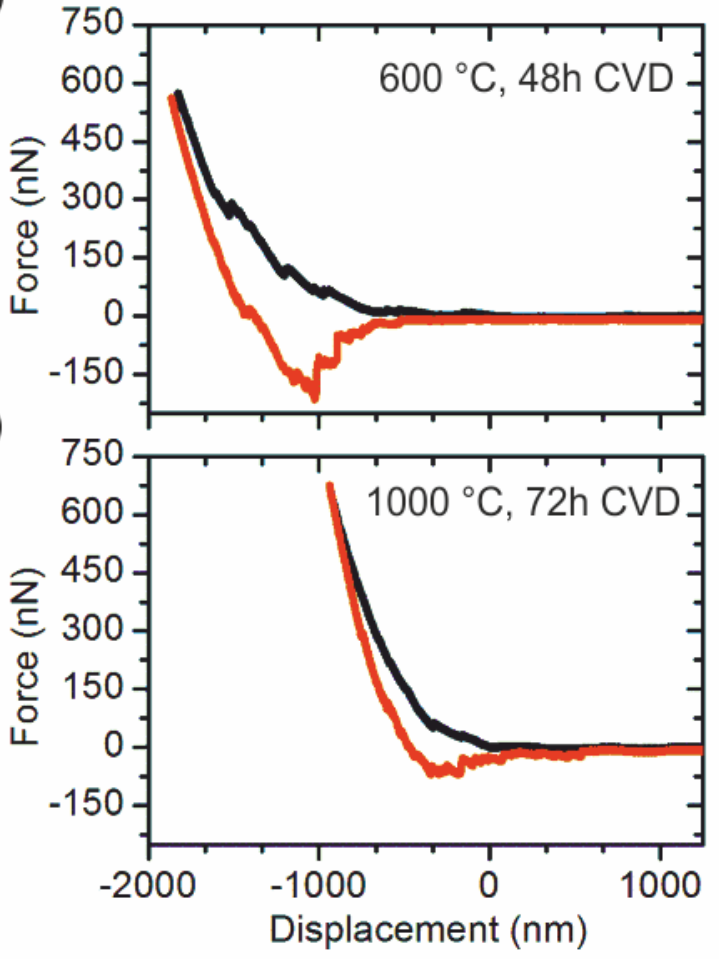

Figure 6: Force-displacement curves of soot-templated surfaces indented by a colloidal probe (preload of $300 \mathrm{nN}$ followed by further displacement of 200 $\mathrm{nm})$. (a-c): representative curves of surfaces exposed to different periods of CVD and sintering temperatures: (a) and (c) were exposed for $24 \mathrm{~h}$, (b) for $72 \mathrm{~h}$ CVD. (a) and (b) were sintered at $600{ }^{\circ} \mathrm{C}$, (c) was sintered at $1000{ }^{\circ} \mathrm{C}$, respectively. 
The averaged quantitative mechanical properties are shown in Figure 7. $E_{\text {eff }}$ and $F_{\max }$ increased with the thickness of the silica shell created by CVD and the sintering temperature that lead to further consolidation of the silica particle network. $E_{\text {eff }}$ increased by more than an order of magnitude from $25 \mathrm{kPa}$ up to $985 \mathrm{kPa}$ when samples were exposed to $72 \mathrm{~h}$ CVD and $1000{ }^{\circ} \mathrm{C}$ sintering compared to $24 \mathrm{~h} \mathrm{CVD}$ and $600{ }^{\circ} \mathrm{C}$ sintering (Figure 7a). All samples treated for $48 \mathrm{~h}$ or $72 \mathrm{~h}$ CVD had higher $\mathrm{E}_{\text {eff }}$ than their counterparts treated for $24 \mathrm{~h}$ CVD. Within our experimental accuracy, $\mathrm{E}_{\text {eff }}$ was identical for samples treated for $48 \mathrm{~h}$ and $72 \mathrm{~h}$ CVD, except when sintered at $600{ }^{\circ} \mathrm{C}$. Coated soot showed a higher $E_{\text {eff }}$ than samples sintered at $600{ }^{\circ} \mathrm{C}$. This is attributed to the additional elasticity provided by the encapsulated carbon template that was burned away at $600{ }^{\circ} \mathrm{C}$. After $72 \mathrm{~h}$ CVD the silica shells have become thick enough to dominate the mechanical strength and the presence or absence of the carbon template did no longer affect the mechanical properties. Correspondingly, $\mathrm{E}_{\text {eff }}$ of coated soot and samples sintered at $600{ }^{\circ} \mathrm{C}$ or $800{ }^{\circ} \mathrm{C}$ did not differ significantly, whereas at $1000^{\circ} \mathrm{C} \mathrm{E}_{\text {eff }}$ increased by a factor of more than two.

(a)

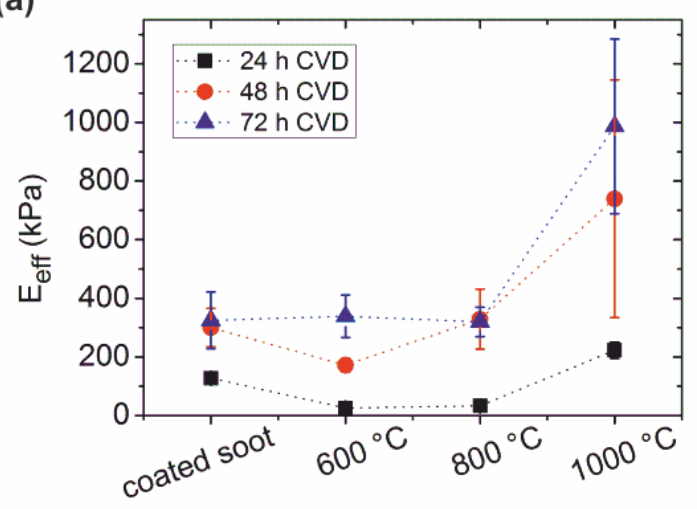

(c)

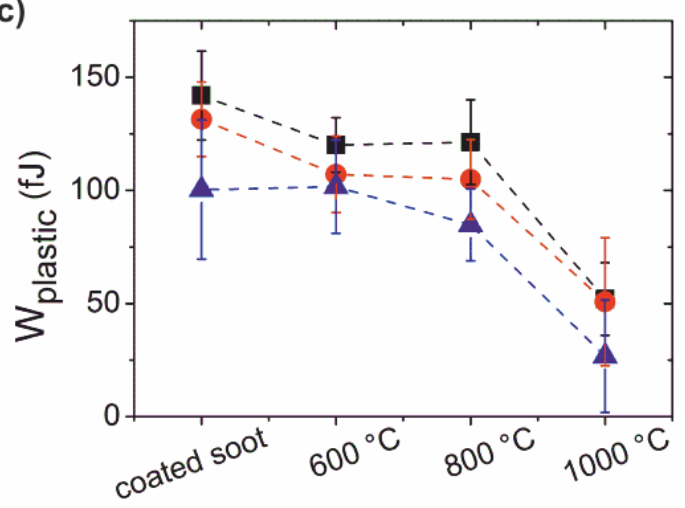

(b)

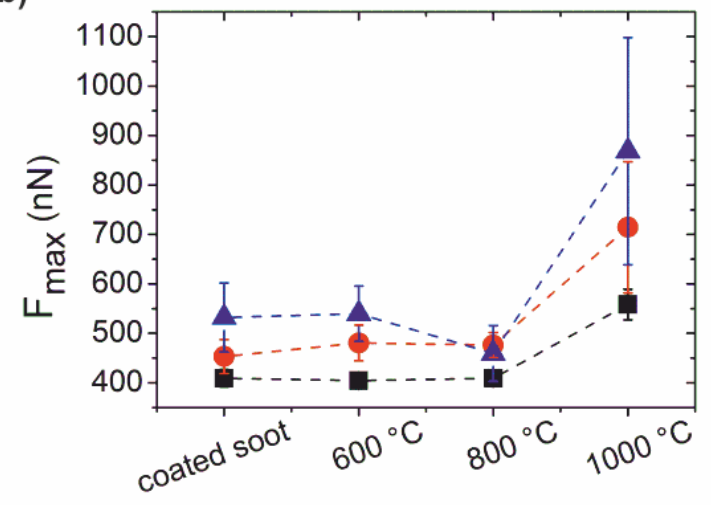

(d)

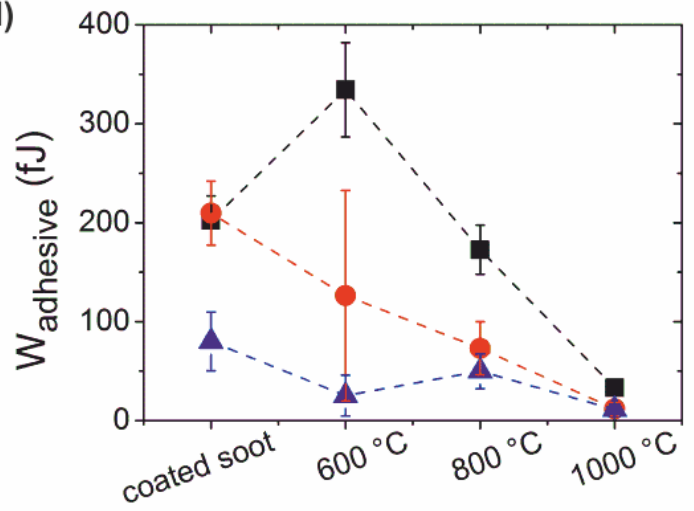

Figure 7: Mechanical properties of soot-templated surfaces. The black, red and blue data points represent surfaces exposed to $24 \mathrm{~h}, 48 \mathrm{~h}$ and $72 \mathrm{~h}$ of CVD, respectively. Coated soot and soot-templated silica surfaces sintered at $600{ }^{\circ} \mathrm{C}, 800{ }^{\circ} \mathrm{C}, 1000{ }^{\circ} \mathrm{C}$ were investigated, respectively. (a) Effective elastic modulus $E_{\text {eff. }}$ (b) Maximum Force $F_{\max }$. (c) Plastic work $W_{\text {plastic }}$ (d) Effective adhesive work $W_{\text {adhesive }}$ The errors are the standard deviations of the respective values obtained from different force curves at different positions on multiple samples. 
$F_{\text {max }}$ increased by a factor of more than two from $400 \mathrm{nN}$ up to $900 \mathrm{nN}$ for samples exposed to $72 \mathrm{~h} \mathrm{CVD}, 1000{ }^{\circ} \mathrm{C}$ compared to $24 \mathrm{~h} \mathrm{CVD}, 600{ }^{\circ} \mathrm{C}$ (Figure $7 \mathrm{~b}$ ). Similarly to $\mathrm{E}_{\text {eff, samples }}$ treated for $48 \mathrm{~h}$ and $72 \mathrm{~h} \mathrm{CVD}$ showed higher $\mathrm{F}_{\max }$ than their counterparts treated for $24 \mathrm{~h}$ CVD. The strongest increase of $F_{\max }$ was found when samples were sintered at $1000^{\circ} \mathrm{C}$.

$W_{\text {plastic }}$ and $W_{\text {adhesive }}$ were in the order of hundreds of femto Joules (Figure $7 c$ and $d$ ). $W_{\text {plastic }}$ and $W_{\text {adhesive }}$ both decreased with increasing thickness of the silica shell and sintering temperature. $W_{\text {plastic }}$ decreased by a factor of more than $4, W_{\text {adhesive }}$ by a factor of about 30 ( $24 \mathrm{~h} \mathrm{CVD}, 600^{\circ} \mathrm{C}$ compared to $72 \mathrm{~h} \mathrm{CVD}, 1000^{\circ} \mathrm{C}$ ).

Samples sintered at $1000{ }^{\circ} \mathrm{C}$ showed a higher hardness and resisted better to the indentation. With increasing hardness the structural differences in the network at every indentation point became more and more relevant. Consequently, the results from individual force-displacement curves showed a broader span of mechanical strength, leading to increased error bars of $E_{\text {eff }}$ and $F_{\max }$ at $1000^{\circ} \mathrm{C}$.

The hardness of samples sintered at $1150{ }^{\circ} \mathrm{C}$ exceeded the force measurement range of the colloidal probe.

\section{Microscale test at high elasticity: Nanoindentation}

Nanoindentation and AFM are complementary and cover different ranges of normal forces and $E_{\text {eff. }}$ Typical nanoindenters span a range of $E_{\text {eff }}$ from $10 \mathrm{MPa}$ to more than $100 \mathrm{GPa}$. Therefore, nanoindentation was not suitable for the sample sintered $\leq 1000^{\circ} \mathrm{C}$ but it was appropriate for samples sintered at $1150^{\circ} \mathrm{C}$. Figure 8 a shows a typical force-displacement curve of a surface exposed to $72 \mathrm{~h} \mathrm{CVD}$. Distinct force jumps in the order of several $\mu \mathrm{N}$ can be identified in the approach part, indicating a collapse of a part of the layer. $E_{\text {eff }}$ as function of the time of CVD for $1150{ }^{\circ} \mathrm{C}$ is shown in Figure $8 \mathrm{~b}$. $\mathrm{E}_{\text {eff }}$ increased by a factor of more than 3 from approximately $300 \mathrm{MPa}$ to more than $1 \mathrm{GPa}$ when increasing CVD time to $72 \mathrm{~h}$.

(a)

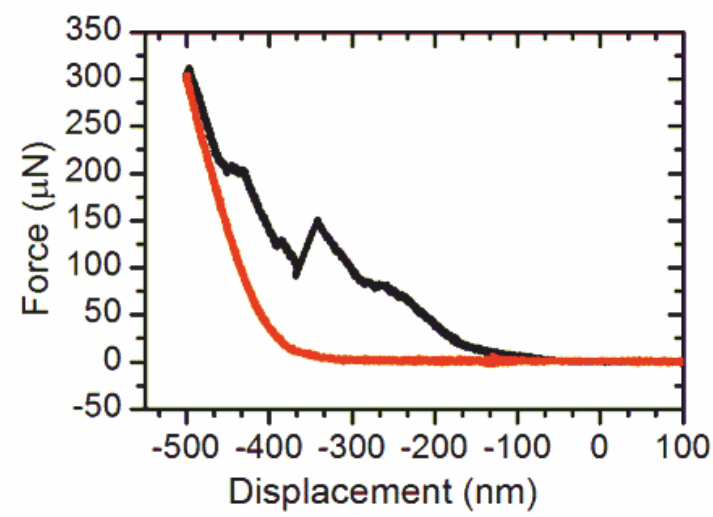

(b)

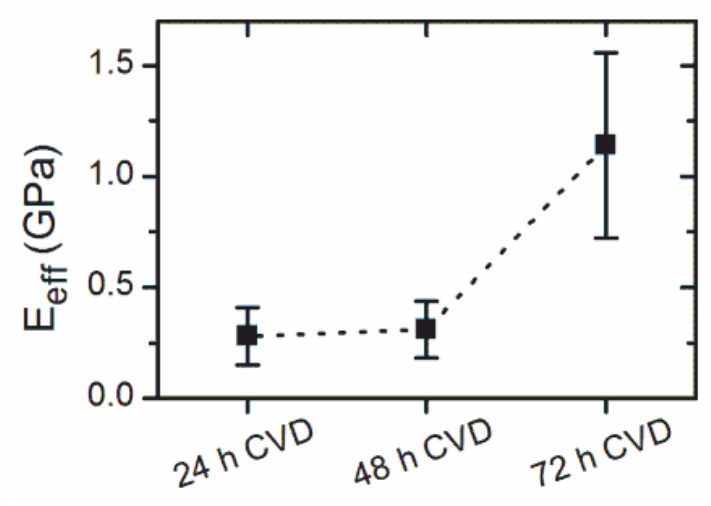

Fig. 8: Nanoindentation of superamphiphobic surfaces sintered at $1150{ }^{\circ} \mathrm{C}$ with a conical diamond tip. (a) Typical force-displacement curve of a surface exposed to $72 \mathrm{~h} \mathrm{CVD}$ indented for $500 \mathrm{~nm}$. Black curve: approach, red curve: retraction (b) $E_{\text {eff }}$ of surfaces exposed to $24 \mathrm{~h}$, $48 \mathrm{~h}$ and $72 \mathrm{~h}$ CVD. 
Comparing the quantitative mechanical test results to the measurements of the roll-off angle from Figure $\mathbf{1 b}$ and the receding contact angle Figure $1 \mathrm{c}$, we conclude that the best combination of superamphiphobicity and mechanical stability is obtained when samples are treated for $48 \mathrm{~h} \mathrm{CVD}$ and sintered at $1000{ }^{\circ} \mathrm{C}$. In this case, the surfaces were still super repellent against $n$-hexadecane while $E_{\text {eff }}$ was increased by a factor of 30 from $25 \mathrm{kPa}$ to 750 $\mathrm{kPa}$ compared to surfaces prepared by $24 \mathrm{~h} \mathrm{CVD}$ and sintered at $600{ }^{\circ} \mathrm{C}$. The observed increase of stability for sintering temperatures of $1000^{\circ} \mathrm{C}$ is attributed to a condensation of $\mathrm{OH}$ groups from the silica network combined with the initial stage of sintering, where the overall morphology of the silica agglomerate network is only slightly changed. Therefore, the network starts to condense ${ }^{[46]}$ but the overall morphology is largely preserved, including the protrusions as shown in Figure 3 e.

\section{Conclusions}

For a comprehensive characterization of the mechanical strength of super liquid-repellent surfaces, different methods need to be used, because different length and force scales need to be adressed. Finger and pencil scratching can provide a first impression of the surfaces stability. Nevertheless comparison of samples having a similar stability can be challenging. Atomic force microscopy reveals the mechanical response of individual protrusions, e.g. the yield force. For surfaces, where the distance between protrusion is smaller than $10 \mu \mathrm{m}$ the colloidal probe technique can be applied to obtain the averaged mechanical strength. The radius of the colloidal probe needs to be much larger then the distance between neighboring protrusions and the depth of indentation should be below $10 \%$ of the thickness of the coating. We propose four parameters which describe the mechanical response of super liquid-repellent surfaces: The effective elastic modulus $E_{\text {eff, }}$ the maximum force $F_{\text {max }}$, the plastic work of indentation $W_{\text {plastic }}$ and the adhesive work $W_{\text {adhesive }}$. The colloidal probe technique is suitable for layers with an effective elastic modulus up to roughly $1 \mathrm{MPa}$. For harder surfaces nanoindentation is suitable.

For a particular liquid-repellent surface, i.e. soot-templated superamphiphobic surfaces we measured the mechanical properties. The aim was to balance them with the wetting properties and to find the optimal compromise. The mechanical strength could be improved by increasing the duration of CVD and the sintering temperature. By this, superamphiphobic surfaces with a 30 fold increased $E_{\text {eff }}$ were prepared compared to the standard samples (750 $\mathrm{kPa}$ for $48 \mathrm{~h} \mathrm{CVD}, 1000{ }^{\circ} \mathrm{C}$ compared to $25 \mathrm{kPa}$ for $24 \mathrm{~h} \mathrm{CVD}, 600{ }^{\circ} \mathrm{C}$ ). A further increase of the sintering temperature to $1150{ }^{\circ} \mathrm{C}$ led to superhydrophobic surfaces of greatly increased mechanical strength ( $E_{\text {eff }}$ of about $1 \mathrm{GPa}$ ). However, liquid repellency decreased and the surfaces lost their superamphiphobic properties. Thus, for superamphiphobic applications, $48 \mathrm{~h} \mathrm{CVD}$ and $1000^{\circ} \mathrm{C}$ sintering is the best compromise and leads to optimal performance. 


\section{Experimental part:}

Tetraethylorthosilicate (TEOS, 98\%), trichloro $(1 \mathrm{H}, 1 \mathrm{H}, 2 \mathrm{H}, 2 \mathrm{H}$-perfluorooctyl)silane (PFOTS, 97\%) and $n$-hexadecane (99\%) were purchased from Sigma-Aldrich, Germany. Toluene and acetone was provided from Fischer Scientific, UK. Ammonium hydroxide aqueous solution Normapur (28\%) and absolute ethanol was received from VWR Chemicals, France. Water was purified by a Sartorius Arium 611. Paraffin candles were obtained from the local supermarket. Silicon wafers were purchased from Si-Mat, Germany. All reagents were used as received.

Superamphiphobic surfaces were prepared according to Deng et al.. ${ }^{[26]}$ Si-wafers were supersonicated in toluene, acetone and ethanol for at least $5 \mathrm{~min}$, respectively, and activated by oxygen plasma for $5 \mathrm{~min}$ at $300 \mathrm{~mW}$. Wafers were coated with TEOS deposited from the gas phase to promote adhesion of the superamphiphobic surface. Therefore the wafers were placed in a desiccator containing an open vial with $3 \mathrm{ml}$ of TEOS and another open vial with aqueous ammonia solution. After $24 \mathrm{~h}$ the precoating was covered with candle soot collected from a paraffin candle about $1 \mathrm{~cm}$ above the wick for $40 \mathrm{~s}$ (wick height $0.7 \mathrm{~cm}$, total flame height $4.5 \mathrm{~cm})^{[47]}$. The carbon template was coated with silica by exposure to TEOS as stated above for different periods of CVD, namely $24 \mathrm{~h}, 48 \mathrm{~h}$ and $72 \mathrm{~h}$. TEOS and aqueous ammonia solution were renewed every $24 \mathrm{~h}$. The total thickness of the silica shell deposited on a smooth surface was determined by ellispometry (Nanofilm surface analysis EP3, $532 \mathrm{~nm}, 50 \mathrm{~mW}$ ) and was found to be $35 \pm 1 \mathrm{~nm}, 71 \pm 2 \mathrm{~nm}$ and $100 \pm 2 \mathrm{~nm}$ for 24 $\mathrm{h}, 48 \mathrm{~h}$ and $72 \mathrm{~h} \mathrm{CVD}$, respectively. On the rough soot-templated silica surfaces the average silica shell thickness was $20 \pm 5 \mathrm{~nm}, 35 \pm 5 \mathrm{~nm}$ and $60 \pm 5 \mathrm{~nm}$ for $24 \mathrm{~h}, 48 \mathrm{~h}$ and $72 \mathrm{~h} \mathrm{CVD}$, respectively. ${ }^{[26]}$ The soot template remained part of the sample (coated soot) or samples were sintered at $600,800,1000$ or $1150{ }^{\circ} \mathrm{C}$ (soot-templated silica) for $3 \mathrm{~h}$, respectively, exclusive heat up time at maximum heat up speed $\left(15^{\circ} \mathrm{C} / \mathrm{min}\right)$. For mechanical tests, the samples were not hydrophobized, i.e. they remained hydrophilic. To measure the contact angles, the samples were hydrophobized. Therefore, samples were placed in a desiccator, next to a $20 \mathrm{ml}$ vial containing $100 \mu \mathrm{l}$ PFOTS. After $3 \mathrm{~h}$ at $25 \mathrm{mbar}$ the samples were ready to use.

Scanning electron microscopy (SEM) images were acquired at a voltage of $1 \mathrm{kV}$ (topview) and $0.7 \mathrm{kV}$ (cross sections) using the InLens detector (LEO $1530 \mathrm{Gemini}$ ). To enhance the image quality the samples were sputtered with $6 \mathrm{~nm}$ Pt (BalTec MED 020 Modular High Vacuum Coating System, Argon at $2 \times 10^{-2} \mathrm{mbar}$ and $60 \mathrm{~mA}$ ). A Tecnai F20 DEI, $200 \mathrm{kV}$, brightfield was used for TEM measurements.

Receding contact angles and roll-off angles were measured using a goniometer (Dataphysics OCA 35, Data Physics Instrument GmbH, Germany). To measure the receding contact angle, an initial drop of $10 \mu \mathrm{l}$ hexadecane was deposited on a surface and inflated/deflated by adding/removing $20 \mu$ l hexadecane, respectively. Receding contact angles were determined by manual ellipse fitting. To determine the roll-off angles drops of $6 \mu$ l water and hexadecane were deposited on the surfaces, respectively. The stage was tilted at a speed of 
$1.37 \%$ s. For both, receding contact angle and tilting angle measurements 3-4 different spots per sample and 2-5 samples were investigated per combination of period of CVD and temperature.

Pencil scratch testing: All samples were scratched with a 6B pencil (Faber-Castell, Germany) at an angle of $45^{\circ}$ by a hand load of approximately $10 \mathrm{~g}$. Scratches were investigated by optical microscopy and SEM.

AFM: Force-displacement curves were recorded with cantilevers having a nominal resonance frequency of $f=70 \mathrm{kHz}$ and a spring constant of $k=2 \mathrm{~N} / \mathrm{m}$ (OMCL-AC240TS, $n$-type doped silicon, Japan) were used. The experimental spring constants were determined by the thermal tune method. Force scans of $64 \times 64$ pixels on an area of $10 \times 10 \mu \mathrm{m}^{2}$ were recorded. A set point of $6 \mathrm{nN}$ was chosen. All AFM and colloidal probe experiments were conducted on a JPK Nanowizard 3.

Colloidal probe: Hollow glass microspheres were glued to tipless cantilever. The hollow glass microspheres were purchased from Cospheric, USA and had a diameter of $47 \mu \mathrm{m}$ (measured by SEM), a mean density of about $0.22 \mathrm{~g} / \mathrm{cc}$ and a crush strength of approximately $2 \mathrm{MPa}$ (according to supplier). The tipless cantilevers were obtained from AppNano ACL-TL, USA $(f=190 \mathrm{kHz})$. The colloidal probes were hydrophobized for $30 \mathrm{~min}$ under the same conditions as stated above. The spring constants were measured by the thermal noise method and ranged from $44-71 \mathrm{~N} / \mathrm{m}$. Force maps of $3 \times 3$ pixels over an area of $150 \times 150 \mu \mathrm{m}^{2}$ were measured. Approach and retraction speeds were $1 \mu \mathrm{m} / \mathrm{s}$ with an extension delay of $0.5 \mathrm{~s} .45-$ 81 force curves on at least 3 samples at various positions were recorded for each combination of CVD time and sintering temperature. The first force-displacement curve of each force map was discarded due to the required surface approach. Four measurement series with different colloidal probes were conducted. Each series started with indentation of the most stable surfaces $\left(72 \mathrm{~h} \mathrm{CVD}, 1000^{\circ} \mathrm{C}\right.$ ) to the weakest surfaces ( $24 \mathrm{~h} \mathrm{CVD}, 600{ }^{\circ} \mathrm{C}$ ). A total of 5-9 force maps were recorded on at least 3 different samples leading to 40-72 force curves per each pair of sintering temperature and period of CVD. For each series of experiments, reference force curves on a silicon wafer were taken. All force-distance curves were analyzed using a self-written LabVIEW software, where first the reference force curves were used to determine the deflection sensitivity. Consecutively, this deflection sensitivity was used to convert deflection signals in volts to cantilever deflections in nanometers, which in turn were converted to force by multiplying with the spring constant. Cantilever deflection was substracted from the piezo position signal, to obtain distance and zero distance was defined as the onset of repulsive force during approach. The effective elastic modulus $E_{\text {eff }}$ was determined by fitting the first $10 \%$ of the retract curve using the Hertz model. This initial part of the retract curve should reflect the elastic recovery of the material during unloading, whereas the approach curve and the later part of the retract curve will contain mixed contributions of elastic and plastic deformation. As additional quantities, the work of plastic deformation $W_{\text {plastic, }}$ the maximum Force $F_{\max }$ at maximum approach and the effective work of adhesion $W_{\text {adhesion }}$ were analyzed as shown in Figure $\mathbf{5}$ and $\mathbf{6 a}$. It should be noted that the 
effective work of adhesion calculated here is not a defined thermodynamic quantity like the Dupré work of adhesion, since the relaxation processes occurring during retraction are irreversible. However, as long as cantilevers with the same spring constant are used, this quantity can give relative information on the adhesiveness of the sample.

Nanoindentation measurements were performed with a standard-force MFP Nanolndenter (Asylum Research, Santa Barbara, CA, spring constant $k=2390 \mathrm{~N} / \mathrm{m}$ ) equipped with a conical diamond tip $\left(r=25 \mu \mathrm{m}\right.$, opening angle $\left.=60^{\circ}\right)$. Samples sintered at $1150{ }^{\circ} \mathrm{C}$ were indented in displacement-controlled mode with maximum displacements of 50, 100, 200, 300 and 500 $\mathrm{nm}$ at a penetration rate in the range of $10-100 \mathrm{~nm} / \mathrm{s}$. Thermal drift was measured and corrected for each indentation. The thicknesses of the indented surfaces were verified by cross-sectional SEM images. The thicknesses ranged from 4, 6.5 and $8 \mu \mathrm{m}$ for samples exposed to $24 \mathrm{~h}, 48 \mathrm{~h}$ and $72 \mathrm{~h} C V D$, sintered at $1150^{\circ} \mathrm{C}$. For $24 \mathrm{~h} \mathrm{CVD}$, we found a substrate effect for indentation depth $>100 \mathrm{~nm}$. In this case $E_{\text {eff }}$ was only averaged over 50 and $100 \mathrm{~nm}$ indentation depth. $E_{\text {eff }}$ was analyzed in analogy to colloidal probe indentation experiments and a spherical contact geometry was assumed.

\section{Acknowledgment:}

We thank G. Glasser, G. Schäfer and Katrin Kirchhoff for technical support, and G. Auernhammer, S. Weber, R. Berger for stimulating discussions. HJB wishes to thank the ERC for the advanced grant 340391-SUPRO. Financial support from SPP 1420 (HJB), SPP1486 (DV, $\mathrm{RF}$ ) is gratefully acknowledged.

[1] T. Sun, L. Feng, X. Gao, L. Jiang, Accounts of Chemical Research 2005, 38, 644.

[2] X. M. Li, D. Reinhoudt, M. Crego-Calama, Chemical Society Reviews 2007, 36, 1350.

[3] N. J. Shirtcliffe, G. McHale, S. Atherton, M. I. Newton, Advances in Colloid and Interface Science 2010, 161, 124.

[4] Z. Chu, S. Seeger, Chemical Society Reviews 2014, 43, 2784.

[5] L. Yao, J. He, Progress in Materials Science 2014, 61, 94.

[6] W. Barthlott, C. Neinhuis, Planta 1997, 202, 1.

[7] J. L. Wang, A. Raza, Y. Si, L. X. Cui, J. F. Ge, B. Ding, J. Y. Yu, Nanoscale 2012, 4, 7549.

[8] M. Paven, P. Papadopoulos, S. Schöttler, X. Deng, V. Mailänder, D. Vollmer, H.-J. Butt, Nat Commun 2013, 4.

[9] B. J. Privett, J. Youn, S. A. Hong, J. Lee, J. Han, J. H. Shin, M. H. Schoenfisch, Langmuir 2011, 27, 9597.

[10] A. B. D. Cassie, S. Baxter, T Faraday Soc 1944, 40, 0546.

[11] J. Bico, C. Marzolin, D. Quéré, Europhys. Lett. 1999, 47, 220.

[12] H.-J. Butt, D. Vollmer, P. Papadopoulos, Advances in Colloid and Interface Science 2015, 222, 104.

[13] S. Herminghaus, EPL (Europhysics Letters) 2000, 52, 165.

[14] A. Tuteja, W. Choi, J. M. Mabry, G. H. McKinley, R. E. Cohen, Proceedings of the National Academy of Sciences 2008, 105, 18200. 
[15] H. J. Butt, C. Semprebon, P. Papadopoulos, D. Vollmer, M. Brinkmann, M. Ciccotti, Soft Matter 2013, 9, 418.

[16] J. A. Greenwood, J. B. P. Williamson, Proceedings of the Royal Society of London A: Mathematical, Physical and Engineering Sciences 1966, 295, 300.

[17] T. Verho, C. Bower, P. Andrew, S. Franssila, O. Ikkala, R. H. A. Ras, Adv Mater 2011, 23, 673.

[18] C.-H. Xue, J.-Z. Ma, Journal of Materials Chemistry A 2013, 1, 4146.

[19] B. P. Dyett, A. H. Wu, R. N. Lamb, ACS Applied Materials \& Interfaces 2014, 6, 18380.

[20] Q. Xie, J. Xu, L. Feng, L. Jiang, W. Tang, X. Luo, C. C. Han, Adv Mater 2004, 16, 302.

[21] H. Wang, J. Fang, T. Cheng, J. Ding, L. Qu, L. Dai, X. Wang, T. Lin, Chemical Communications $2008,877$.

[22] D. Xiong, G. J. Liu, L. Z. Hong, E. J. S. Duncan, Chem Mater 2011, 23, 4357.

[23] E. Yoshida, Colloid Polym Sci 2012, 290, 525.

[24] N. Valipour Motlagh, R. Khani, S. Rahnama, Colloids and Surfaces A: Physicochemical and Engineering Aspects 2015, 484, 528.

[25] H. Teisala, M. Tuominen, M. Stepien, J. Haapanen, J. Mäkelä, J. Saarinen, M. Toivakka, J. Kuusipalo, Cellulose 2013, 20, 391.

[26] X. Deng, L. Mammen, H. J. Butt, D. Vollmer, Science 2012, 335, 67.

[27] Y. Lu, S. Sathasivam, J. Song, C. R. Crick, C. J. Carmalt, I. P. Parkin, Science 2015, 347, 1132.

[28] J. Groten, J. Rühe, Langmuir 2013, 29, 3765.

[29] Y. C. Jung, B. Bhushan, ACS Nano 2009, 3, 4155.

[30] I. Malavasi, I. Bernagozzi, C. Antonini, M. Marengo, Surface Innovations 2015, 3, 49.

[31] G. Binnig, C. F. Quate, C. Gerber, Physical Review Letters 1986, 56, 930.

[32] H.-J. Butt, B. Cappella, M. Kappl, Surface Science Reports 2005, 59, 1.

[33] W. C. Oliver, G. M. Pharr, Journal of Materials Research 1992, 7, 1564.

[34] W. A. Ducker, T. J. Senden, R. M. Pashley, Nature 1991, 353, 239.

[35] H. J. Butt, Biophysical Journal 1991, 60, 1438.

[36] M. Kappl, H.-J. Butt, Particle \& Particle Systems Characterization 2002, 19, 129.

[37] S. O. Schopf, S. Salameh, L. Madler, Nanoscale 2013, 5, 3764.

[38] D. Vijayshankar, L. Mammen, P. Papadopoulos, D. Vollmer, RSC Advances 2014, 4, 12737.

[39] M. D. Sacks, T.-Y. Tseng, Journal of the American Ceramic Society 1984, 67, 532.

[40] C. J. Brinker, G. W. Scherer, Sol-gel science: the physics and chemistry of sol-gel processing, Academic press, 1990.

[41] J. Frenkel, Journal of Physics (Moscow) 1945, 9, 385.

[42] H.-J. Butt, M. Kappl, Surface and interfacial forces, John Wiley \& Sons, 2009.

[43] J. N. Israelachvili, Intermolecular and surface forces: revised third edition, Academic press, 2011.

[44] L.-O. Heim, J. Blum, M. Preuss, H.-J. Butt, Physical Review Letters 1999, 83, 3328.

[45] L. O. Heim, H. J. Butt, J. Blum, R. Schräpler, Granular Matter 2008, 10, 89.

[46] L. Zhang, M. D'Acunzi, M. Kappl, A. Imhof, A. v. Blaaderen, H.-J. Butt, R. Graf, D. Vollmer, Physical Chemistry Chemical Physics 2010, 12, 15392.

[47] M. Paven, P. Papadopoulos, L. Mammen, X. Deng, H. Sachdev, D. Vollmer, H.-J. Butt, pac 2014, 86, 87. 